\title{
Pemberian $\mathrm{CaCO}_{3}$ pada media bersalinitas $3 \mathrm{~g} / \mathrm{L}$ untuk pertumbuhan ikan bawal air tawar
}

\author{
Addition of $\mathrm{CaCO}_{3}$ to culture media at the salinity of $3 \mathrm{~g} / \mathrm{L}$ for \\ freshwater tambaqui growth
}

\author{
Yuni Puji Hastuti*, Chandra Yudistira, Kukuh Nirmala, Wildan Nurusallam, \\ Kurnia Faturochman
}

\author{
Departemen Budidaya Perairan, Fakultas Perikanan dan Ilmu Kelautan, Institut Pertanian Bogor \\ Kampus IPB Dramaga Bogor, Jawa Barat 16680 \\ *Surel: yuni_ph2@yahoo.com
}

\begin{abstract}
Increasing of freshwater tambaqui Colossoma macropomum demand makes the farmers increase the production of the consumption fish and seed. Acceleration of the production cycle can increase total production level, and reduce the level of osmotic work can be used to improve fish growth. This study aimed to analyze the effect of the addition of calcium carbonate $\left(\mathrm{CaCO}_{3}\right)$ in the saline medium of $3 \mathrm{~g} / \mathrm{L}$ on the growth of freshwater tambaqui juvenile. Tambaqui used has a body length of $1.93 \pm 0.1 \mathrm{~cm}$ and weight of $0.26 \pm 0.03 \mathrm{~g}$. The experiment used 15 units of aquarium at size of $30 \times 15 \times 25 \mathrm{~cm}^{3}$ and filled with $9 \mathrm{~L}$ of saline water, then added lime $\mathrm{CaCO}_{3}$ according to treatment. The treatments were control $(0 \mathrm{mg} / \mathrm{L} \mathrm{CaCO})_{3}, \mathrm{~A}(50 \mathrm{mg} / \mathrm{L} \mathrm{CaCO}), \mathrm{B}\left(100 \mathrm{mg} / \mathrm{L} \mathrm{CaCO}_{3}\right), \mathrm{C}(150$ $\left.\mathrm{mg} / \mathrm{L} \mathrm{CaCO}_{3}\right)$, and $\mathrm{D}\left(200 \mathrm{mg} / \mathrm{L} \mathrm{CaCO}_{3}\right)$. The study was conducted for 30 days of maintenance. Fishes were fed on bloodworms ad libitum or provided three times a day. The results showed that survival, daily growth rate, and absolute length growth of the $\mathrm{CaCO}_{3}$ treatments significantly higher $(\mathrm{P}<0.05)$ that that of control. Furthermore, survival, daily growth rate, and absolute length growth among the $\mathrm{CaCO}_{3}$ treatments were the same. Thus, addition $\mathrm{CaCO}_{3}$ of $50 \mathrm{mg} / \mathrm{L}$ saline water of $3 \mathrm{~g} / \mathrm{L}$ can be applied to increase culture performance of freshwater tambaqui.
\end{abstract}

Keywords: freshwater tambaqui, $\mathrm{CaCO}_{3}$, salinity

\begin{abstract}
ABSTRAK
Permintaan terhadap ikan bawal air tawar Colossoma macropomum yang semakin meningkat membuat pembudidaya menambah produksi ikan konsumsi dan benih. Percepatan siklus produksi dapat meningkatkan total produksi budidaya, dan energi dari optimasi kerja osmotik dapat dialokasikan untuk pertumbuhan. Penelitian ini bertujuan untuk menganalisis pengaruh penambahan kalsium karbonat $\left(\mathrm{CaCO}_{3}\right)$ pada media bersalinitas terhadap pertumbuhan benih ikan bawal air tawar. Benih ikan bawal yang digunakan memiliki panjang $1,93 \pm 0,1$ $\mathrm{cm}$ dengan bobot $0,26 \pm 0,03 \mathrm{~g}$. Akuarium yang digunakan berukuran $30 \times 15 \times 25 \mathrm{~cm}^{3}$ sebanyak 15 unit dan diisi air bersalinitas $3 \mathrm{~g} / \mathrm{L}$ sebanyak $9 \mathrm{~L}$, kemudian ditambahkan kapur $\mathrm{CaCO}_{3}$ sesuai perlakuan. Dosis setiap perlakuan terdiri atas kontrol (0 mg/L CaCO $), \mathrm{A}\left(50 \mathrm{mg} / \mathrm{L} \mathrm{CaCO}_{3}\right), \mathrm{B}(100 \mathrm{mg} / \mathrm{L} \mathrm{CaCO}$ ), C (150 mg/L CaCO $)$, dan D (200 $\mathrm{mg} / \mathrm{L} \mathrm{CaCO}_{3}$ ). Penelitian dilakukan selama 30 hari pemeliharaan dengan pemberian pakan cacing sutra secara ad libitum atau diberikan tiga kali sehari. Hasil penelitian menunjukkan bahwa derajat kelangsungan hidup, laju pertumbuhan harian, dan panjang mutlak pada perlakuan penambahan kapur $\mathrm{CaCO}_{3}$ lebih tinggi $(\mathrm{P}<0,05)$ daripada kontrol. Sementara itu, derajat kelangsungan hidup, laju pertumbuhan harian, dan panjang mutlak antarperlakuan penambahan kapur $\mathrm{CaCO}_{3}$ tidak berbeda. Dengan demikian, penambahan $\mathrm{CaCO}_{3}$ sebanyak $50 \mathrm{mg} / \mathrm{L}$ air dapat diterapkan untuk perbaikan performa budidaya ikan.
\end{abstract}

Kata kunci: ikan bawal air tawar, $\mathrm{CaCO}_{3}$, salinitas

\section{PENDAHULUAN}

Ikan bawal air tawar Colossoma macropomum merupakan salah satu jenis ikan air tawar asal Brazil yang terbesar dari golongan ikan neotropik. Saat ini, Direktorat Jenderal Perikanan Budidaya di Indonesia sedang mengembangkan produksi ikan bawal air tawar karena setiap tahun mengalami peningkatan produksi. Produksi ikan bawal air tawar di Provinsi Jawa Barat pada tahun 
2010 sebesar 7.343 ton dengan jumlah benih yang ditebar sebesar 542.118.000 ekor masih belum mencukupi permintaan pasar (KKP, 2011). Peningkatan produksi tersebut harus diimbangi dengan peningkatan benih yang cukup jumlah dan mutu serta kontinu. Pemenuhan benih ikan bawal masih menjadi kendala dalam kegiatan pembenihan, karena tingkat kematian mencapai 10-20\% dari mulai telur menetas hingga ukuran 2 inci.

Ketersediaan benih dipengaruhi beberapa faktor, yaitu faktor internal (waktu matang kelamin dan siklus pemijahan) serta faktor eksternal (teknologi pembenihan). Peningkatan kualitas dan kuantitas benih dapat dilakukan melalui teknologi pembenihan dengan melakukan rekayasa wadah penetasan, nutrisi pakan dan rekayasa lingkungan. Pengaruh lingkungan terhadap produksi hewan air adalah bersifat ganda, sedangkan sifat genetik dan faktor lainnya bersifat tunggal serta faktor-faktor tersebut bersifat interaktif dan kumulatif. Salinitas merupakan salah satu parameter kualitas air yang diharapkan dapat meningkatkan kelayakan media budidaya bagi benih ikan bawal air tawar karena berpengaruh secara langsung pada kelangsungan hidup, konsumsi pakan, pertumbuhan dan metabolisme tubuh terutama osmoregulasi.

Lingkungan bersalinitas $3 \mathrm{~g} / \mathrm{L}$ pada pemeliharaan ikan bawal akan menjadikan kondisi lingkungan mendekati isoosmotik sehingga memperkecil penggunaan energi untuk osmoregulasi kemudian dialihkan untuk pertumbuhan. Sel organ tubuh ikan dapat berfungsi dengan baik saat sel-sel tersebut harus berada dalam cairan media (ekstraseluler) yang memiliki komposisi dan konsentrasi ionik yang sama dengan cairan dalam sel (intraseluler). Salah satu cara yang dapat dilakukan adalah dengan memanipulasi kadar kalsium media pemeliharaan (Hastuti et al., 2012). Menurut Fontagné et al. (2009) kalsium berperan sebagai kofaktor berbagai jenis enzim serta berperan dalam meningkatkan aktivitas saraf. Berdasarkan penelitian yang telah dilakukan menunjukkan penambahan kalsium pada wadah budidaya dapat meningkatkan tingkat kelangsungan hidup dan pertumbuhan udang galah (Zaidy et al., 2008; Hadie et al., 2009), udang vaname (Kaligis et al., 2009), dan ikan patin (Hastuti et al., 2012).

Kalsium merupakan mineral esensial yang diperlukan dalam jumlah yang cukup banyak. Kebutuhan kalsium dapat dipenuhi dengan penambahan kapur yakni $\mathrm{CaCO}_{3}$ (kalsit),
$\mathrm{CaMg}\left(\mathrm{CO}_{3}\right)_{2}$ (dolomit), dan jenis kapur lainnya seperti $\mathrm{Ca}(\mathrm{OH})_{2}$ dan $\mathrm{CaO}$. Penelitian ini bertujuan untuk menganalisis pengaruh penambahan kalsium karbonat $\left(\mathrm{CaCO}_{3}\right)$ pada media bersalinitas terhadap pertumbuhan benih ikan bawal air tawar C. macropomum.

\section{BAHAN DAN METODE}

Ikan uji yang digunakan adalah benih ikan bawal air tawar dengan panjang rata-rata $1,93 \pm 0,105 \mathrm{~cm}$ dan bobot rata-rata $0,26 \pm 0,03$ g, yang diperoleh dari pengepul di Taufan Fish Farm, Pomad, Kabupaten Bogor. Adapun bahan yang digunakan untuk media adalah garam krosok dan kapur $\mathrm{CaCO}_{3}$.

\section{Rancangan percobaan}

Rancangan penelitian yang digunakan adalah rancangan acak lengkap dengan lima perlakuan, masing-masing diulang sebanyak tiga kali. Perlakuan yang diberikan berupa pemberian kapur $\mathrm{CaCO}_{3}$ sebanyak $0 \mathrm{mg} / \mathrm{L} \mathrm{CaCO}$ (kontrol), $50 \mathrm{mg} / \mathrm{L} \mathrm{CaCO}_{3}(\mathrm{~A}), 100 \mathrm{mg} / \mathrm{L} \mathrm{CaCO}_{3}$ (B), 150 $\mathrm{mg} / \mathrm{L} \mathrm{CaCO}_{3}(\mathrm{C})$, dan $200 \mathrm{mg} / \mathrm{L} \mathrm{CaCO}_{3}$ (D) ke dalam media bersalinitas $3 \mathrm{~g} / \mathrm{L}$.

\section{Persiapan media dan wadah pemeliharaan}

Wadah yang digunakan pada penelitian ini adalah 15 unit akuarium berdimensi $30 \times 15 \times$ $25 \mathrm{~cm}^{3}$. Akuarium yang sudah disiapkan diisi dengan air bersalinitas $3 \mathrm{~g} / \mathrm{L}$ sebanyak $9 \mathrm{~L}$, Kapur yang digunakan adalah $\mathrm{CaCO}_{3}$ dalam bentuk bubuk, kemudian diberikan perlakuan dengan penambahan kapur $\mathrm{CaCO}_{3}$ yang terdiri atas kontrol $\left(0 \mathrm{mg} / \mathrm{L} \mathrm{CaCO}_{3}\right), \mathrm{A}\left(50 \mathrm{mg} / \mathrm{L} \mathrm{CaCO}_{3}\right), \mathrm{B}$ $(100 \mathrm{mg} / \mathrm{L} \mathrm{CaCO})_{3}, \mathrm{C}\left(150 \mathrm{mg} / \mathrm{L} \mathrm{CaCO}_{3}\right)$ dan $\mathrm{D}$ $(200 \mathrm{mg} / \mathrm{L} \mathrm{CaCO})_{3}$ ) dengan masing-masing tiga ulangan, kemudian media diaerasi selama 24 jam.

\section{Pemeliharaan ikan uji}

Wadah yang telah disiapkan kemudian digunakan untuk memelihara benih ikan bawal air tawar C. macropomum dengan ukuran panjang $1,93 \pm 0,1 \mathrm{~cm}$ dengan bobot $0,26 \pm 0,03$ $\mathrm{g}$ dimasukkan masing-masing sebanyak 4 ekor/L atau 36 ekor/akuarium dan dilakukan aklimatisasi. Ikan dipelihara selama 30 hari dan diberikan pakan cacing sutra secara ad libitum.

Pemberian pakan dilakukan dengan frekuensi tiga kali sehari yaitu pagi, siang, dan sore hari secara ad libitum. Pergantian air sebanyak 25$30 \%$ dari total volume air setiap tiga hari sekali dilakukan untuk mempertahankan kualitas air 
dalam media pemeliharaan. Kemudian dilakukan pengisian kembali air yang terbuang dengan air yang berasal dari akuarium stok sesuai dengan konsentrasi perlakuan. Pengukuran parameter kualitas air dilakukan setiap sepuluh hari sekali yang meliputi oksigen terlarut (DO), suhu, $\mathrm{pH}$, amonia, kesadahan total, dan kesadahan $\mathrm{Ca}^{2+}$. Pengukuran pertumbuhan dilakukan setiap tujuh hari sekali dengan parameter pengamatan berupa panjang dan bobot benih ikan bawal air tawar dengan mengukur sebanyak sepuluh ekor ikan per akuarium. Selain itu, dilakukan pengukuran kandungan mineral $\mathrm{Ca}^{2+}$ dalam tubuh ikan (proksimat mineral) pada awal dan akhir penelitian.

\section{Derajat kelangsungan hidup}

Derajat kelangsungan hidup merupakan presentase ikan yang hidup, penghitungan nilai sintasan ikan menggunakan rumus sebagai berikut:

$$
\mathrm{SR}=\mathrm{Nt} / \mathrm{No} \times 100
$$

$$
\begin{aligned}
& \text { Keterangan : } \\
& \begin{aligned}
\mathrm{SR}= & \text { derajat kelangsungan hidup }(\%) \\
\mathrm{Nt}= & \text { jumlah individu pada akhir perlakuan } \\
& \text { hari ke-t (ekor) } \\
\mathrm{No}= & \text { jumlah individu pada awal perlakuan } \\
& \text { (ekor) }
\end{aligned}
\end{aligned}
$$

\section{Laju pertumbuhan harian/(LPH)}

Laju pertumbuhan harian atau specific growth rate (SGR) pada benih presentase penambahan bobot setiap harinya selama pemeliharaan. LPH dihitung dengan menggunakan rumus sebagai berikut:

$$
\mathrm{SGr}=\left[(\mathrm{Wt} / \mathrm{Wo})^{-\mathrm{t}}-1\right] \times 100
$$

\section{Keterangan:}

$$
\begin{aligned}
& \mathrm{SGR}=\text { laju pertumbuhan harian }(\% / \text { hari }) \\
& \mathrm{Wt}=\text { bobot rata-rata pada akhir perlakuan } \\
& \quad(\mathrm{g}) \\
& \mathrm{Wo}= \\
& \quad(\mathrm{g}) \\
& \mathrm{t} \quad=\text { periode pemeliharaan (hari) }
\end{aligned}
$$

\section{Panjang mutlak}

Panjang mutlak (g/hari) adalah pertambahan bobot ikan setiap harinya selama pemeliharaan. Rumus yang digunakan yaitu:

$$
\mathrm{PM}=\mathrm{Pt}-\mathrm{Po}
$$

\section{Keterangan:}

GR = pertambahan mutlak $(\mathrm{g} / \mathrm{hari})$

$\mathrm{Pt}=$ bobot rata-rata ikan pada saat akhir (g)

Po $=$ bobot rata-rata ikan pada saat awal (g)

\section{Analisis data}

Penelitian menggunakan rancangan percobaan berupa rancangan acak lengkap dengan empat perlakuan dan tiga kali ulangan. Data yang diperoleh diolah dengan Microsoft Excel 2010, kemudian dilakukan uji ANOVA menggunakan program komputer SPSS 17.0 untuk melihat perbedaan antarperlakuan.

\section{HASIL DAN PEMBAHASAN}

\section{Hasil}

\section{Derajat kelangsungan hidup}

Derajat kelangsungan hidup pada benih ikan bawal air tawar yang dipelihara selama 30 hari memiliki hasil yang berbeda antara perlakuan $\mathrm{CaCO}_{3}$ dengan kontrol, sedangkan antarperlakuan $\mathrm{CaCO}_{3}$ adalah sama. Kelangsungan hidup ikan perlakuan $\mathrm{CaCO}_{3}$ berkisar antara $75 \%$ dan $85 \%$, sedangkan kelangsungan hidup ikan kontrol adalah 70,73\% (Gambar 1).

\section{Laju pertumbuhan harian}

Laju pertumbuhan harian ikan bawal air tawar diamati selama 30 hari pada masingmasing perlakuan. Nilai laju pertumbuhan harian semua perlakuan mengalami peningkatan setiap minggunya. Laju pertumbuhan harian

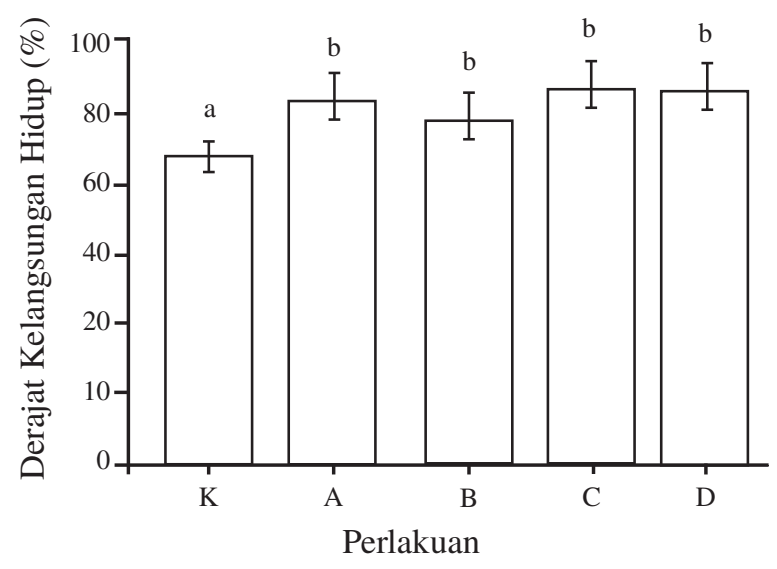

Gambar 1. Derajat kelangsungan hidup ikan bawal air tawar Colossoma macropomum. Huruf yang berbeda menunjukkan hasil yang berbeda nyata $(\mathrm{P}<0,05)$. $\mathrm{K}$ (tanpa penambahan $\mathrm{CaCO}_{3}$ ), A (penambahan 50 $\mathrm{mg} / \mathrm{L} \mathrm{CaCO}_{3}$ ), B (penambahan $100 \mathrm{mg} / \mathrm{L} \mathrm{CaCO}_{3}$ ), C (penambahan $150 \mathrm{mg} / \mathrm{L} \mathrm{CaCO}_{3}$ ) dan $\mathrm{D}$ (penambahan $200 \mathrm{mg} / \mathrm{L} \mathrm{CaCO}_{3}$ ). 
ikan perlakuan $\mathrm{CaCO}_{3}$ lebih tinggi dibandingkan dengan kontrol, sedangkan antarperlakuan $\mathrm{CaCO}_{3}$ adalah sama. Laju pertumbuhan ikan perlakuan $\mathrm{CaCO}_{3}$ berkisar antara $8,5 \%$ dan 9,7\%/hari, sedangkan kontrol 7,68 \%/hari (Gambar 2).

\section{Bobot rata-rata}

Pengamatan terhadap perlakuan yang dilakukan selama 28 hari memberikan peningkatan bobot rata-rata ikan bawal air tawar secara konstan dari bobot rata-rata awal 0,26 $\pm 0,03$ g/ekor. Bobot rata-rata ikan perlakuan $\mathrm{CaCO}_{3}$ lebih tinggi dibandingkan dengan kontrol, sedangkan antarperlakuan $\mathrm{CaCO}_{3}$ adalah sama. Bobot rata-rata ikan perlakuan $\mathrm{CaCO}_{3}$ berkisar antara $3 \mathrm{~g} / \mathrm{ekor}$ dan 3,5 g/ekor, sedangkan bobot rata-rata kontrol adalah 2,18 g/ekor (Gambar 3).

\section{Panjang mutlak}

Pertumbuhan panjang mutlak benih ikan bawal air tawar selama masa pemeliharaan untuk setiap perlakuan memiliki perbedaan. Panjang mutlak terting gi diperoleh perlakuan D $(200 \mathrm{mg} / \mathrm{L}$ $\mathrm{CaCO}_{3}$ ) dengan nilai 2,64 cm, sedangkan panjang mutlak terendah diperoleh perlakuan kontrol $(0$ $\mathrm{mg} / \mathrm{L} \mathrm{CaCO}_{3}$ ) dengan nilai $1,87 \mathrm{~cm}$ (Gambar 4).

\section{Panjang rata-rata}

Pengamatan terhadap perlakuan yang dilakukan selama 28 hari menunjukkan peningkatan panjang rata-rata ikan bawal air tawar secara konstan dari panjang rata-rata awal $1,93 \pm 0,1 \mathrm{~cm} /$ ekor. Peningkatan panjang rata-rata tertinggi terdapat pada perlakuan D $(200 \mathrm{mg} / \mathrm{L}$ $\mathrm{CaCO}_{3}$ ) sebesar 4,6 cm/ekor, dan terendah pada kontrol dengan nilai 3,8 cm/ekor (Gambar 5).

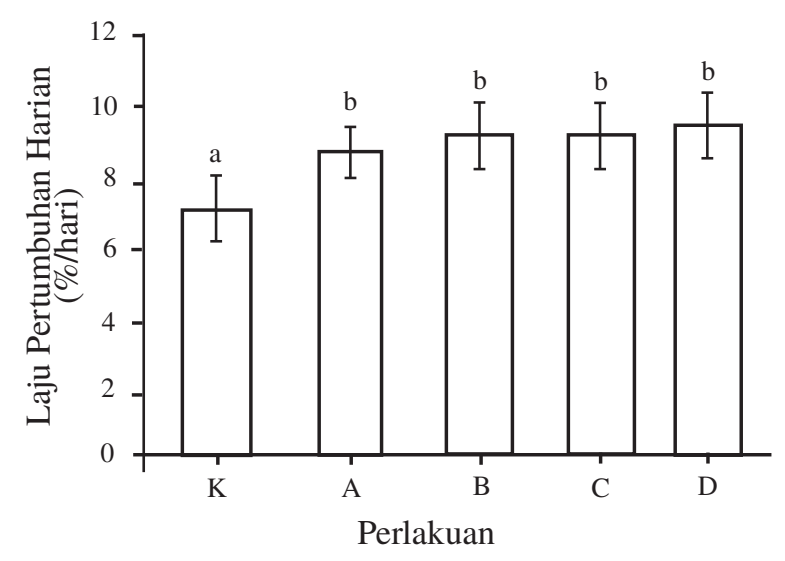

Gambar 2. Laju pertumbuhan harian benih ikan bawal air tawar Colossoma macropomum. Keterangan: K (tanpa penambahan $\mathrm{CaCO}_{3}$ ), A (penambahan 50 $\mathrm{mg} / \mathrm{L} \mathrm{CaCO}_{3}$ ), B (penambahan $100 \mathrm{mg} / \mathrm{L} \mathrm{CaCO}_{3}$ ), C (penambahan $150 \mathrm{mg} / \mathrm{L} \mathrm{CaCO}_{3}$ ) dan $\mathrm{D}$ (penambahan $200 \mathrm{mg} / \mathrm{L} \mathrm{CaCO}_{3}$ ).
Kandungan kalsium pada benih ikan bawal

Kandungan $\mathrm{Ca}^{2+}$ benih ikan bawal air tawar yang dianalisis pada akhir masa pemeliharaan menunjukkan nilai yang sama pada semua perlakuan. Kandungan $\mathrm{Ca}^{2+}$ ikan berkisar antara 0,59\%-0,68\%. Secara umum, kandungan $\mathrm{Ca}^{2+}$ pada benih ikan bawal air tawar meningkat dari persentase awal sebelum perlakuan yaitu sebesar 0,47\% (Gambar 6).

\section{Nilai $p H$}

Grafik berikut menunjukkan nilai $\mathrm{pH}$ setiap perlakuan yang memiliki nilai kisaran 6,52-8,15. Pengukuran $\mathrm{pH}$ yang dilakukan selama pemeliharaan memiliki nilai yang stabil, meskipun mengalami penurunan hingga akhir pemeliharaan (Gambar 7).

\section{Oksigen terlarut}

Pengukuran konsentrasi oksigen terlarut selama pemeliharaan memiliki nilai yang stabil, meskipun mengalami peningkatan pada hari pertama dan menurun hingga akhir pemeliharaan. Konsentrasi oksigen terlarut berkisar antara 5,20$6,93 \mathrm{mg} / \mathrm{L}$ (Gambar 8).

\section{Suhu}

Pengukuran suhu yang dilakukan memiliki perubahan pada nilai di masing-masing perlakuan. Nilai suhu selama pemeliharaan berkisar antara $24,80-26,77{ }^{\circ} \mathrm{C}$ (Gambar 9).

\section{Amonia}

Pengukuran konsentrasi amonia yang dilakukan selama pemeliharaan berkisar antara 0,001-0,039 $\mathrm{mg} / \mathrm{L} \mathrm{NH}_{3}$. Konsentrasi amonia

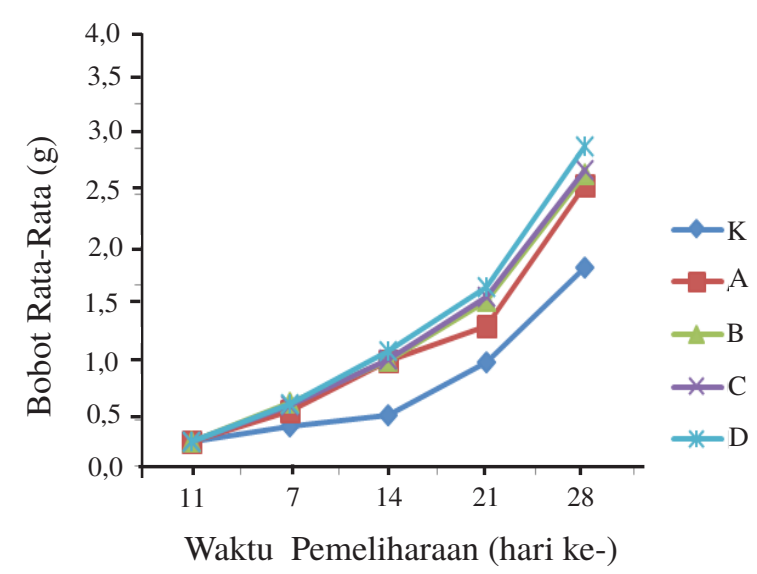

Gambar 3. Bobot rata-rata benih ikan bawal air tawar Colossoma macropomum. Keterangan: K (tanpa penambahan $\mathrm{CaCO}_{3}$ ), A (penambahan 50 $\mathrm{mg} / \mathrm{L} \mathrm{CaCO}_{3}$ ), B (penambahan $100 \mathrm{mg} / \mathrm{L} \mathrm{CaCO}_{3}$ ), C (penambahan $150 \mathrm{mg} / \mathrm{L} \mathrm{CaCO}_{3}$ ) dan $\mathrm{D}$ (penambahan $200 \mathrm{mg} / \mathrm{L} \mathrm{CaCO}_{3}$ ). 
pada semua perlakuan mengalami penurunan dihari kesepuluh sampai akhir pemeliharaan (Gambar 10).

\section{Kesadahan total}

Kesadahan total yang diukur selama pemeliharaan menurun hingga akhir pemelihraan kecuali pada perlakuan kontrol $\left(0 \mathrm{mg} / \mathrm{L} \mathrm{CaCO}_{3}\right)$ yang cenderung mengalami fluktuasi. Kisaran nilai kesadahan total pada awal pemelihraan adalah 149,48-392,39 mg/L CaCO 3 dan menurun pada hari ke-10 dengan kisaran nilai 59,76$317,65 \mathrm{mg} / \mathrm{L} \mathrm{CaCO}_{3}$. Nilai kesadahan kembali menurun pada akhir pemeliharaan dengan kisaran 82,22-239, 17 mg/L $\mathrm{CaCO}_{3}$ (Gambar 11).

\section{Kesadahan $\mathrm{Ca}^{2+}$}

Kesadahan $\mathrm{Ca}^{2+}$ yang diukur selama pemeliharaan memiliki nilai yang fluktuatif pada semua perlakuan. Nilai kesadahan pada awal pemeliharaan sampai hari ke-20 cenderung meningkat dengan kisaran nilai 78,48-22,49 $\mathrm{mg} / \mathrm{L} \mathrm{CaCO}_{3}$ dan mengalami penurunan pada hari ke-30 dengan kisaran nilai 41,11-142,01 $\mathrm{mg} / \mathrm{L} \mathrm{CaCO}_{3}$ (Gambar 12).

\section{PEMBAHASAN}

Kelangsungan hidup ikan uji di dalam lingkungan yang berkadar garam bergantung pada permukaan insang, laju konsumsi oksigen, toleransi jaringan tubuh terhadap garam-garam dan kontrol permeabilitas. Selain itu, permberian lingkungan bersalinitas kepada ikan air tawar dapat meningkatkan daya tahan dan kelangsungan hidup ikan menjadi 95-100\% (DiMaggio et

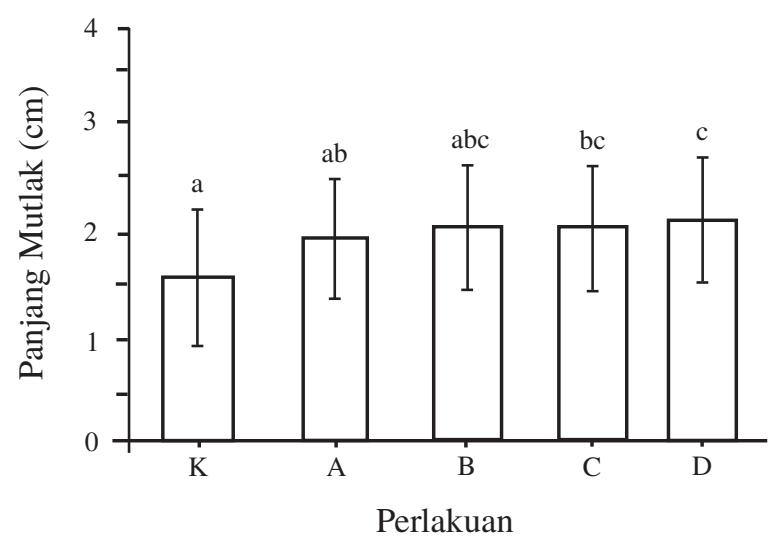

Gambar 4. Panjang mutlak benih ikan bawal air tawar Colossoma macropomum. Huruf yang berbeda menunjukkan hasil yang berbeda nyata $(\mathrm{P}<0,05)$ $\mathrm{K}$ (tanpa penambahan $\mathrm{CaCO}_{3}$ ), A (penambahan 50 $\mathrm{mg} / \mathrm{L} \mathrm{CaCO}_{3}$ ), B (penambahan $100 \mathrm{mg} / \mathrm{L} \mathrm{CaCO}_{3}$ ), C (penambahan $150 \mathrm{mg} / \mathrm{L} \mathrm{CaCO}_{3}$ ) dan $\mathrm{D}$ (penambahan $200 \mathrm{mg} / \mathrm{L} \mathrm{CaCO}_{3}$ ). $a l$, 2009). Hal ini sesuai dengan hasil yang didapatkan bahwa benih ikan bawal air tawar dapat hidup lebih baik dan lebih tahan terhadap penyakit pada lingkungan bersalinitas. Pemberian garam pada lingkungan budidaya memberikan pengaruh nyata terhadap kontrol. Kelangsungan hidup ikan perlakuan $\mathrm{CaCO}_{3}$ berkisar antara $75 \%$ dan $85 \%$, sedangkan kelangsungan hidup ikan kontrol adalah 70,73\% (Gambar 1).

Pertumbuhan merupakan pertambahan bobot atau panjang. Menurut Azaza et al. (2006) menyatakan bahwa pertumbuhan dipengaruhi oleh beberapa faktor seperti faktor internal yang terdiri atas daya tahan terhadap penyakit dan genetik, serta faktor eksternal yang berkaitan dengan lingkungan tempat hidup serta ketersediaan makanan. Penelitian ini menguji faktor eksternal dengan cara menambahkan kapur $\mathrm{CaCO}_{3}$ ke dalam lingkungan benih ikan bawal air tawar. Berdasarkan analisis, penambahan kapur $\mathrm{CaCO}_{3}$ tidak memberikan pengaruh nyata terhadap laju pertumbuhan bobot harian benih bawal, namun berbeda nyata dengan kontrol yang tidak diberikan penambahan kapur $\mathrm{CaCO}_{3}$. Menurut Shahsavarani et al. (2006) menyatakan bahwa kalsium dapat diserap oleh tubuh melalui insang dan kulit. Laju pertumbuhan ikan perlakuan $\mathrm{CaCO}_{3}$ berkisar antara $8,5 \%$ dan $9,7 \%$ /hari, sedangkan laju pertumbuhan ikan kontrol adalah 7,68 \%/hari (Gambar 2). Berdasarkan hasil perlakuan tersebut, ikan bawal mampu memanfaatkan mineral $\mathrm{Ca}^{2+}$ dalam perairan yang dapat digunakan sebagai pertumbuhan. Laju pertumbuhan harian terendah diperoleh perlakuan kontrol $\left(0 \mathrm{mg} / \mathrm{L} \mathrm{CaCO}_{3}\right)$ dengan nilai 7,68\% (Gambar 2). Sedikitnya

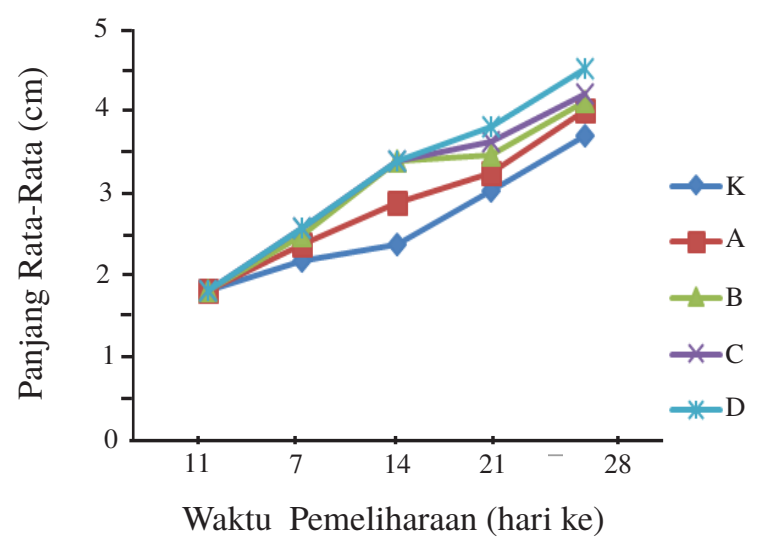

Gambar 5. Panjang rata-rata benih ikan bawal air tawar Colossoma macropomum. K (tanpa penambahan $\mathrm{CaCO}_{3}$ ), A (penambahan $50 \mathrm{mg} / \mathrm{L} \quad \mathrm{CaCO}_{3}$ ), B (penambahan $100 \mathrm{mg} / \mathrm{L} \mathrm{CaCO}_{3}$ ), $\mathrm{C}$ (penambahan 150 $\mathrm{mg} / \mathrm{L} \mathrm{CaCO}_{3}$ ) dan $\mathrm{D}$ (penambahan $200 \mathrm{mg} / \mathrm{L} \mathrm{CaCO}_{3}$ ). 


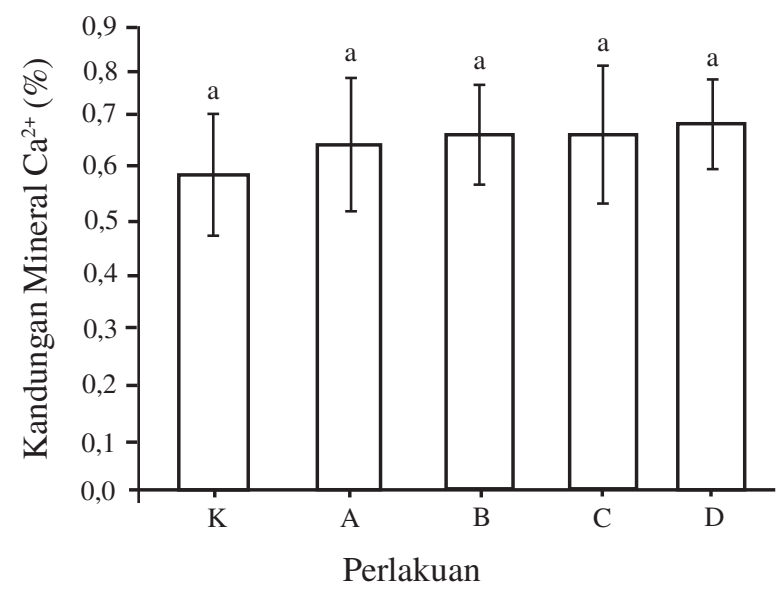

Gambar 6. Kandungan mineral $\mathrm{Ca}^{2+}$ benih ikan bawal air tawar Colossoma macropomum. Huruf yang sama menunjukkan hasil yang tidak berbeda nyata $(\mathrm{P}>0,05)$. $\mathrm{K}$ (tanpa penambahan $\mathrm{CaCO}_{3}$ ), A (penambahan 50 $\mathrm{mg} / \mathrm{L} \mathrm{CaCO}_{3}$ ), B (penambahan $100 \mathrm{mg} / \mathrm{L} \mathrm{CaCO}_{3}$ ), C (penambahan $150 \mathrm{mg} / \mathrm{L} \mathrm{CaCO}_{3}$ ) dan $\mathrm{D}$ (penambahan $200 \mathrm{mg} / \mathrm{L} \mathrm{CaCO}_{3}$ ).
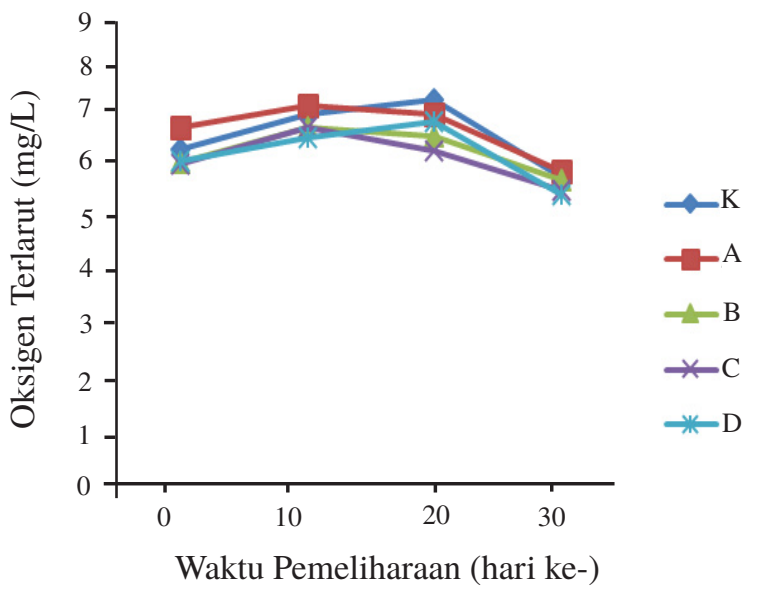

Gambar 8. Konsentrasi oksigen terlarut air pemeliharaan ikan bawal tawar. K (tanpa penambahan $\mathrm{CaCO}_{3}$ ), A (penambahan $50 \mathrm{mg} / \mathrm{L} \quad \mathrm{CaCO}_{3}$ ), B (penambahan $100 \mathrm{mg} / \mathrm{L} \mathrm{CaCO}_{2}$ ), $\mathrm{C}$ (penambahan 150 $\mathrm{mg} / \mathrm{L} \mathrm{CaCO}_{3}$ ) dan D (penambahan $200 \mathrm{mg} / \mathrm{L} \mathrm{CaCO}_{3}$ ).

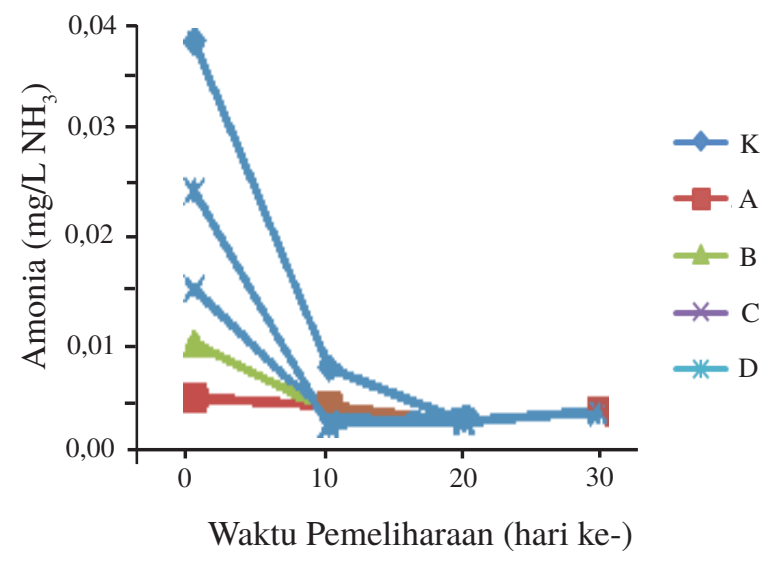

Gambar 10. Konsentrasi amonia air pemeliharaan ikan bawal tawar. $\mathrm{K}$ (tanpa penambahan $\mathrm{CaCO}_{3}$ ), A (penambahan $50 \mathrm{mg} / \mathrm{L} \mathrm{CaCO}_{3}$ ), B (penambahan 100 $\mathrm{mg} / \mathrm{L} \mathrm{CaCO}_{3}$ ), $\mathrm{C}$ (penambahan $150 \mathrm{mg} / \mathrm{L} \mathrm{CaCO}_{3}$ ) dan $\mathrm{D}$ (penambahan $200 \mathrm{mg} / \mathrm{L} \mathrm{CaCO}_{3}$ ).

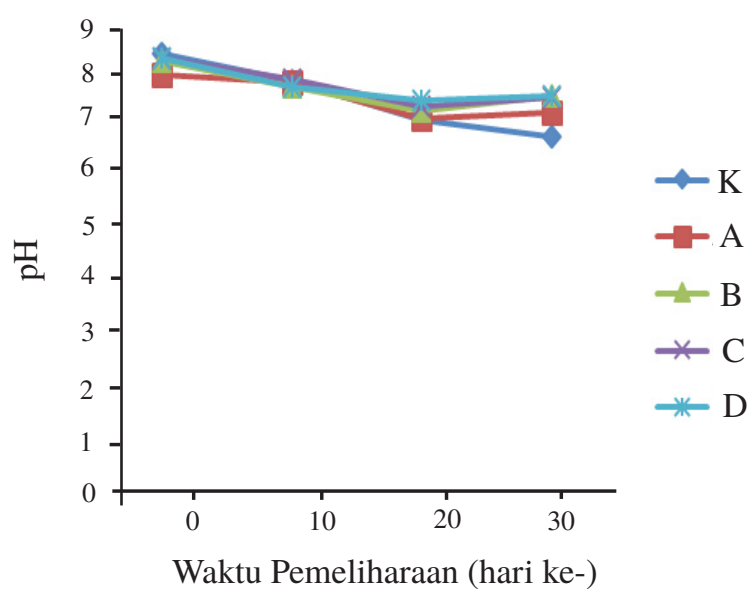

Gambar 7. Kondisi pH air pemeliharaan ikan bawal tawar. $\mathrm{K}$ (tanpa penambahan $\mathrm{CaCO}_{3}$ ), A (penambahan $50 \mathrm{mg} / \mathrm{L} \quad \mathrm{CaCO}_{3}$ ), B (penambahan $100 \mathrm{mg} / \mathrm{L}$ $\mathrm{CaCO}_{3}$ ), C (penambahan $150 \mathrm{mg} / \mathrm{L} \mathrm{CaCO}_{3}$ ) dan $\mathrm{D}$ (penambahan $200 \mathrm{mg} / \mathrm{L} \mathrm{CaCO}_{3}$ ).dan $\mathrm{D}$ (penambahan $200 \mathrm{mg} / \mathrm{L} \mathrm{CaCO}_{3}$ ).

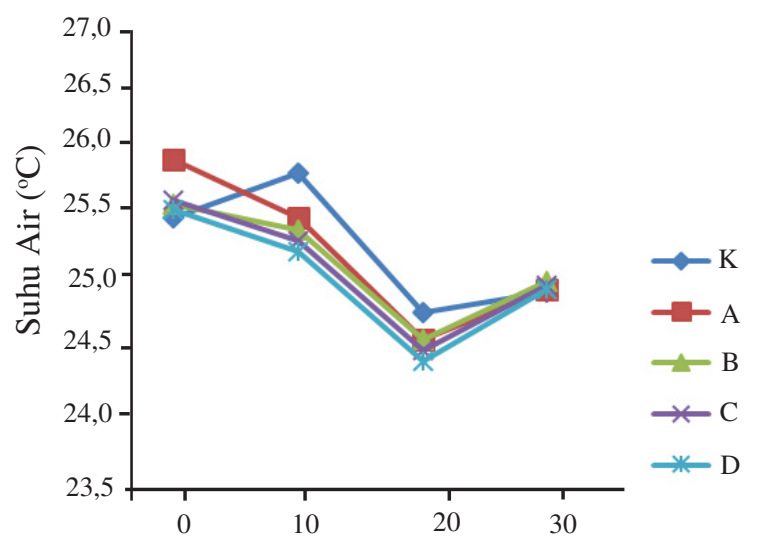

Waktu Pemeliharaan (hari ke-)

Gambar 9 Kondisi suhu air pemeliharaan ikan bawal tawar. $\mathrm{K}$ (tanpa penambahan $\mathrm{CaCO}_{3}$ ), A (penambahan $50 \mathrm{mg} / \mathrm{L} \mathrm{CaCO}_{3}$ ), B (penambahan $100 \mathrm{mg} / \mathrm{L} \mathrm{CaCO}_{3}$ ), C (penambahan $150 \mathrm{mg} / \mathrm{L} \mathrm{CaCO}_{3}$ ), dan D (penambahan $200 \mathrm{mg} / \mathrm{L} \mathrm{CaCO}_{3}$ ).

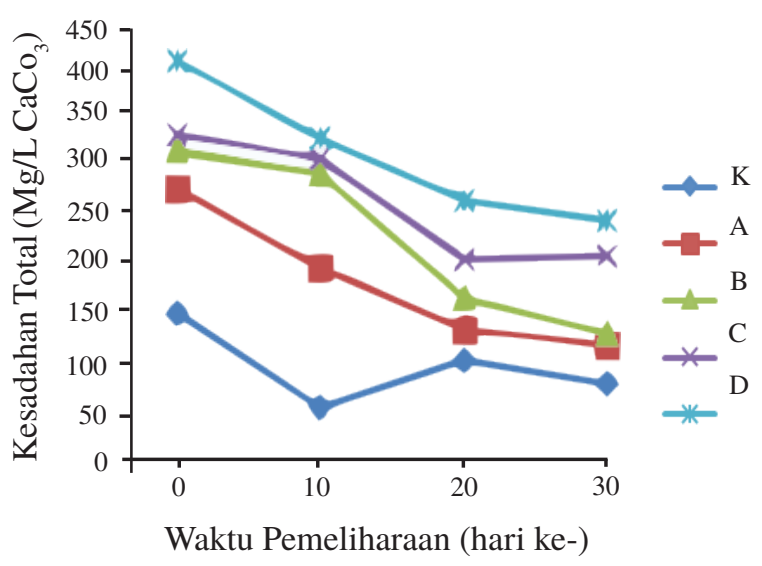

Gambar 11. Nilai kesadahan total air pemeliharaan ikan bawal tawar. $\mathrm{K}$ (tanpa penambahan $\mathrm{CaCO}_{3}$ ), A (penambahan $50 \mathrm{mg} / \mathrm{L} \mathrm{CaCO}_{3}$ ), B (penambahan 100 $\mathrm{mg} / \mathrm{L} \mathrm{CaCO}_{3}$ ), $\mathrm{C}$ (penambahan $150 \mathrm{mg} / \mathrm{L} \mathrm{CaCO}_{3}$ ) dan $\mathrm{D}$ (penambahan $200 \mathrm{mg} / \mathrm{L} \mathrm{CaCO}_{3}$ ). 


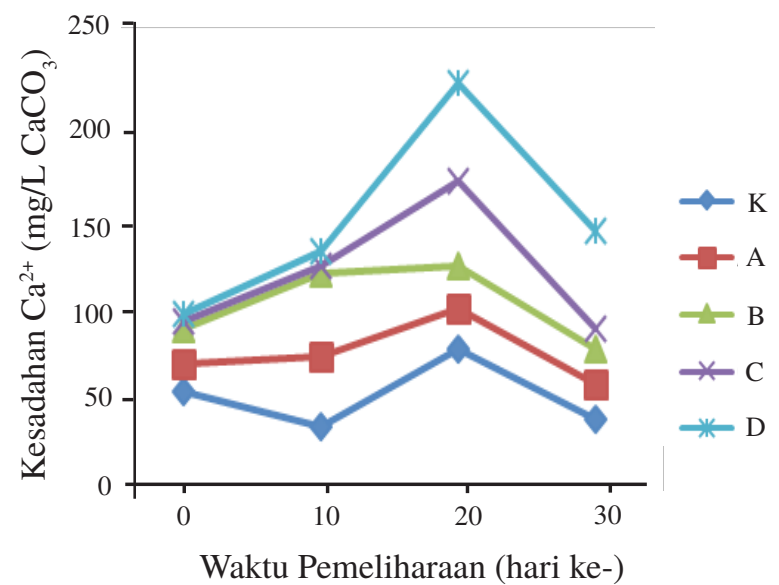

Gambar 12. Nilai kesadahan $\mathrm{Ca}^{2+}$ air pemeliharaan ikan bawal tawar. $\mathrm{K}$ (tanpa penambahan $\mathrm{CaCO}_{3}$ ), $\mathrm{A}$ (penambahan $50 \mathrm{mg} / \mathrm{L} \mathrm{CaCO}_{3}$ ), B (penambahan 100 $\mathrm{mg} / \mathrm{L} \mathrm{CaCO}_{3}$ ), $\mathrm{C}$ (penambahan $150 \mathrm{mg} / \mathrm{L} \mathrm{CaCO}_{3}$ ) dan $\mathrm{D}$ (penambahan $200 \mathrm{mg} / \mathrm{L} \mathrm{CaCO}_{3}$ ).

kandungan mineral $\mathrm{Ca}^{2+}$ yang diserap dari lingkungan, membuat laju pertumbuhan harian ikan pada perlakuan kontrol kurang maksimal. Hal ini sesuai dengan hasil proksimat kandungan mineral $\mathrm{Ca}^{2+}$ yang diserap oleh benih ikan bawal. Perlakuan D (200 mg/L $\left.\mathrm{CaCO}_{3}\right)$ terdapat 0,68\% mineral $\mathrm{Ca}^{2+}$ dalam tubuh, sedangan perlakuan kontrol $\left(0 \mathrm{mg} / \mathrm{L} \mathrm{CaCO}_{3}\right)$ terdapat $0,59 \%$ mineral $\mathrm{Ca}^{2+}$ dalam tubuh (Gambar 6). Penambahan kapur juga memberikan pengaruh nyata terhadap peningkatan bobot rata-rata benih ikan bawal. Hal ini ditunjukkan oleh grafik bobot rata-rata (Gambar 3) yang mengalami peningkatan bobot hingga akhir pemeliharaan. Peningkatan bobot rata-rata tertinggi diperoleh perlakuan D (200 $\mathrm{mg} / \mathrm{L} \mathrm{CaCO}_{3}$ ) yakni berkisar antara 3,25-4,02 g/ekor, sedangkan peningkatan bobot rata-rata terendah diperoleh perlakuan kontrol $(0 \mathrm{mg} / \mathrm{L}$ $\mathrm{CaCO}_{3}$ ) yakni berkisar antara 1,31-3,04 g/ekor.

Pemberian kapur $\mathrm{CaCO}_{3}$ dapat meningkatkan konsentrasi kalsium air yang merupakan unsur penting untuk pertumbuhan ikan dan kesehatan agar mendapatkan pertumbuhan yang baik (de Holanda Cavalcante et al., 2009). Hal ini sesuai dengan hasil yang didapatkan bahwa pemberian kapur $\mathrm{CaCO}_{3}$ pada lingkungan benih ikan bawal memberikan pengaruh yang berbeda nyata terhadap pertumbuhan panjang. Panjang mutlak tertinggi terdapat pada perlakuan D $(200 \mathrm{mg} / \mathrm{L}$ $\mathrm{CaCO}_{3}$ ) yakni sebesar $2,64 \mathrm{~cm}$, sedangkan panjang mutlak terendah terdapat pada perlakuan kontrol $\left(0 \mathrm{mg} / \mathrm{L} \mathrm{CaCO}_{3}\right)$ yakni sebesar $1,87 \mathrm{~cm}$. Selisih pertambahan panjang dari awal pemeliharaan sebesar 1,93 cm sampai akhir pemeliharaan dapat diperkuat dengan peningkatan panjang rata-rata hingga akhir pemeliharaan (Gambar 5). Panjang rata-rata tertinggi terdapat pada perlakuan $\mathrm{D}(200$ $\mathrm{mg} / \mathrm{L} \mathrm{CaCO}_{3}$ ) dengan nilai $4,6 \mathrm{~cm}$, sedangkan yang terendah terdapat pada perlakuan kontrol $(0$ $\mathrm{mg} / \mathrm{L} \mathrm{CaCO}$ ) dengan nilai 3,8 cm (Lampiran 5). Menurut Fontagné et al. (2009) kalsium berperan sebagai kofaktor berbagai jenis enzim serta berperan dalam meningkatkan aktivitas saraf. Berdasarkan data tersebut dapat dilihat bahwa benih ikan bawal air tawar mampu menyerap $\mathrm{Ca}^{2+}$ dari perairan. Perlakuan yang baik dalam menyerap $\mathrm{Ca}^{2+}$ terdapat pada perlakuan D (200 $\mathrm{mg} / \mathrm{L} \mathrm{CaCO}_{3}$ ), dilihat dari grafik pertumbuhan bobot maupun panjang rata-rata selama pemeliharaan yang terus meningkat.

Kualitas air selama pemeliharaan berada pada kisaran optimal untuk pertumbuhan ikan bawal air tawar. Pengaruh suhu terhadap tubuh organisme akuatik memiliki kisaran yang berbeda-beda. Suhu yang didapatkan selama pemeliharaan ikan bawal di semua perlakuan berkisar antara 24,80-26,77 ${ }^{\circ} \mathrm{C}$. Kisaran suhu optimal untuk ikan bawal adalah 27-28 ${ }^{\circ} \mathrm{C}$ sehingga mampu memberikan tingkat kelangsungan hidup, pertumbuhan panjang harian dan laju pertumbuhan bobot harian yang tinggi (Oishi et al., 2010). Perubahan suhu yang semakin menurun dari suhu awal pemeliharaan menyebabkan pertumbuhan dan metabolisme ikan bawal menurun. Hal ini diperkuat dengan grafik suhu yang menunjukkan penurunan suhu terjadi pada hari kesepuluh (Gambar 9). Peningkatan suhu menyebabkan kelarutan oksigen menurun dalam air, mempercepat metabolisme dan respirasi, serta peningkatan konsumsi oksigen. Selain itu, pertumbuhan bawal air tawar akan jauh berkurang apabila suhu air turun di bawah 25 ${ }^{\circ} \mathrm{C}$. Ikan bawal air tawar tergolong ke dalam ikan yang kurang toleransi terhadap kadar oksigen terlarut rendah. Pertumbuhan maupun konsumsi pakan akan meningkat dengan meningkatnya suhu dan menurun jika terjadi penurunan suhu dalam jangka pendek (de Carvalho Gomes et al., 2006).

Ikan bawal air tawar memiliki media hidup yang mendekati isoosmotik, sehingga media pemeliharaan menjadi optimal. Salinitas selama pemeliharaan terdapat pada kisaran yang optimal atau mendekati isoosmotik yaitu antara 2,703,20 g/L. Salinitas tersebut diharapkan dapat memberikan kisaran salinitas yang mendekati isoosmotik untuk media hidup ikan bawal air tawar. Selain itu, $\mathrm{pH}$ merupakan indikator yang digunakan untuk mengevaluasi kualitas air. Nilai $\mathrm{pH}$ yang didapatkan selama pemeliharaan masih dalam nilai yang disarankan yaitu berkisar antara 
6,52-8,15. Menurut Aride et al. (2007), ikan bawal air tawar memiliki laju pertumbuhan dan bobot akhir yang lebih tinggi ketika dipelihara pada $\mathrm{pH}$ asam dibandingkan $\mathrm{pH}$ basa. Nilai $\mathrm{pH}$ sangat mempengaruhi proses biokimia perairan, misalnya proses nitrifikasi akan berakhir jika nilai $\mathrm{pH}$ rendah. Berdasarkan nilai $\mathrm{pH}$ yang diperoleh menunjukkan bahwa kapasitas bufer yang terkandung dalam kapur $\mathrm{CaCO}_{3}$ (dolomit) mampu menyangga dan meminimalkan fluktuasi nilai $\mathrm{pH}$. Selama pemeliharaan $\mathrm{pH}$ cenderung menurun hingga akhir pemeliharaan, hal ini disebabkan oleh penurunan suhu dan konsentrasi oksigen terlarut.

Nilai pH yang diamati di semua perlakuan mengalami penurunan sampai akhir pemeliharaan. Hal ini bisa disebabkan oleh penurunan nilai amonia yang semakin menurun hingga akhir pemeliharaan. Konsentrasi amonia yang diperoleh dari semua perlakuan memiliki kisaran 0,001$0,039 \mathrm{mg} / \mathrm{L} \mathrm{NH}_{3}$. Amonium yang dapat terionisasi banyak ditemukan diperarian yang memiliki $\mathrm{pH}$ rendah, sedangkan pada $\mathrm{pH}$ tinggi lebih banyak ditemukan amonia yang tidak terionisasi dan bersifat toksik. Berdasarkan data amonia yang didapatkan, sesuai dengan nilai amonia yang disarankan oleh Keshavanath et al. (2012) yang menyatakan bahwa amonia pada lingkungan pemeliharaan ikan bawal air tawar maksimal $0,1 \mathrm{mg} / \mathrm{L} \mathrm{NH}_{3}$. Pernyataan tersebut disarankan pada kualitas air yang menjadi pembatas yaitu konsentrasi oksigen terlarut. Konsentrasi oksigen terlarut pada pemeliharaan ikan bawal air tawar sebaiknya minimal $4 \mathrm{mg} / \mathrm{L}$ dan optimal pada 7-8 mg/L (Keshavanath et al., 2012). Hal ini sesuai dengan konsentrasi oksigen terlarut yang diamati pada semua perlakuan selama pemeliharaan yaitu berkisar antara 5,20-6,83 mg/L, sehingga sesuai untuk media pemeliharaan ikan bawal air tawar.

Kesadahan menggambarkan kandungan ion $\mathrm{Ca}^{2+}$ dan $\mathrm{Mg}^{2+}$ serta ion polivalen lainnya seperti $\mathrm{Al}^{3+}, \mathrm{Fe}^{3+}, \mathrm{Mn}^{2+}, \mathrm{Sr}^{2+}$ dan $\mathrm{H}^{+}$yang terlarut dalam air. Pemeliharaan ikan bawal memiliki nilai kesadahan yang bervariasi dan dapat dikategorikan sebagai perairan yang menengah $\left(50-150 \mathrm{mg} / \mathrm{L} \mathrm{CaCO}_{3}\right)$, sadah (150-300 mg/L $\mathrm{CaCO}_{3}$ ) dan sangat sadah (lebih dari $300 \mathrm{mg} / \mathrm{L} \mathrm{CaCO}_{3}$ ). Berbeda dengan de Carvalho Gomes et al. (2006) yang menyatakan konsentrasi kesadahan untuk ikan bawal air tawar adalah 6-9 mg/L $\mathrm{CaCO}_{3}$. Konsentrasi kesadahan yang diperoleh dari setiap perlakuan selama pemeliharaan memiliki kisaran 59,76-392,39 $\mathrm{mg} / \mathrm{L} \mathrm{CaCO}_{3}$ dan mengalami penurunan dari pengukuran awal. Kisaran konsentrasi kesadahan pada pengukuran awal antara 149,48-392,39 $\mathrm{mg} / \mathrm{L} \mathrm{CaCO}_{3}$. Kemudian kesadahan menurun hingga akhir pengukuran dengan kisaran antara 82,22-239,17 mg/L $\mathrm{CaCO}_{3}$, sedangkan untuk konsentrasi kesadahan $\mathrm{Ca}^{2+}$ pada awal pemeliharaan memiliki kisaran 56,06-97,16 $\mathrm{mg} / \mathrm{L} \mathrm{CaCO}_{3}$ dan cenderung meningkat sampai hari ke-20 dengan kisaran 78,48-220,49 mg/L $\mathrm{CaCO}_{3}$, kemudian mengalami penurunan hingga akhir pemeliharaan dengan kisaran 41,11-142,01 $\mathrm{mg} / \mathrm{L} \mathrm{CaCO}_{3}$. Menurunnya kadar $\mathrm{Ca}^{2+}$ dalam perairan dapat menunjukkan bahwa ikan bawal mampu memanfaatkan $\mathrm{Ca}^{2+}$ di perairan. Kondisi media pemeliharaan dengan penambahan kapur $\mathrm{CaCO}_{3}$ mampu memberikan pengaruh terhadap pertumbuhan ikan bawal air tawar pada fase pendederan. Hal ini dibuktikan dengan hasil yang didapatkan selama pemeliharaan berlangsung.

\section{KESIMPULAN}

Derajat kelangsungan hidup, laju pertumbuhan bobot dan panjang tubuh benih ikan bawal air tawar yang dipelihara pada media diberi kapur kalsium karbonat $\left(\mathrm{CaCO}_{3}\right)$ dan bersalinitas 3 g/L lebih tinggi daripada kontrol, sedangkan antarperlakuan pemberian kapur adalah tidak berbeda nyata. Dengan demikian, penambahan kapur dapat menggunakan dosis $50 \mathrm{mg} / \mathrm{L}$.

\section{DAFTAR PUSTAKA}

Azaza MS, Dhraief MN, Kraiem MM. 2008. Effects of water temperature on growth and sex ratio of juvenile Nile tilapia Oreochromis niloticus (Linnaeus) reared in geothermal waters in southern Tunisia. Journal of thermal Biology 33: 98-105.

Aride PHR, Roubach R, Val AL. 2007. Tolerance response of tambaqui Colossoma macropomum (Cuvier) to water $\mathrm{pH}$. Aquaculture Research 38: 588-594.

de Carvalho Gomes L, Chagas EC, MartinsJunior H, Roubach R, Ono EA, de Paula Lourenço JN. 2006. Cage culture of tambaqui Colossoma macropomum in a central Amazon floodplain lake. Aquaculture 253: 374-384.

de Holanda Cavalcante D, de Sousa Poliato A, Ribeiro DC, Magalhães FB, do Carmo MV. 2009. Effects of $\mathrm{CaCO}_{3}$ liming on water quality and growth performance of fingerlings of Nile tilapia, Oreochromis niloticus. Animal Sciences 31: 327-333.

DiMaggio MA, Ohs CL, Petty BD. 2009. Salinity 
tolerance of the seminole kilifish Fundulud seminolis a candidate species for marine baitfish aquaculture. Aquaculture 293: 74-80.

Fontagné S, Silva N, Bazin D, Ramos A, Aguirre P, Surget A, Abrantes A, Kaushik JS, Power MB. 2009. Effects of dietary phosphorus and calcium level on growth and skeletal development in rainbow trout Oncorhynchus mykiss fry. Aquaculture 297: 141-150.

Hadie LE, Hadie W, Prihadi TH. 2009. Efektivitas mineral kalsium terhadap pertumbuhan yuwana udang galah Macrobrachium rosenbergii. Jurnal Riset Akuakultur 4: 6572.

Hastuti YP, Djokosetyanto D, Permatasari I. 2012. Penambahan kapur $\mathrm{CaO}$ pada media bersalinitas untuk pertumbuhan benih ikan patin Pangasius hypopthalamus. Jurnal Akuakultur Indonesia 11: 168-178.

Kaligis E, Djokosetiyanlo D, Affandi R. 2009. Pengaruh penambahan kalsium dan salinitas aklimasi terhadap peningkatan sintasan pascalarva udang vaname Litopenaeus vannamei Boone. Jurnal Kelautan Nasional 2: 101-108.

Keshavanath P, Oishi CA, Fonseca FAL. 2012. Growth response of tambaqui Colossoma macropomum fingerlings to salt (sodium chloride) supplemented diets. Journal of Fisheries and Aquatic Science 7: 439-446.

KKP [Kementrian Kelautan dan Perikanan]. 2011. Jumlah produksi perikanan budidaya kolam menurut jenis ikan dan provinsi (2006-2011). http://statistik.kkp.go.id/. [25 September 2013].

Oishi CA, Nwanna LC, Pereira Filho M. 2010. Optimum dietary protein requirement for Amazonian tambaqui Colossoma macropomum Cuvier, 1818, fed fish meal free diets. Acta Amazonica 40: 757-762.

Shahsavarani A, McNeill B, Galvez F, Wood CM, Goss GG, Hwang PP, Perry SF. 2006. Characterization of a branchial epithelial calcium channel (ECaC) in freshwater rainbow trout Oncorhynchus mykiss. Journal of Experimental Biology 209: 1.928-1.943.

Zaidy AB, Affandi R, Kiranadi B, Praptokardiyo K, Manalu W. 2008. Pendayagunaan kalsium media perairan dalam proses ganti kulit dan konsekuensinya bagi pertumbuhan udang galah Macrobrachium rosenbergii de Man. Jurnal Ilmu-Ilmu Perairan dan Perikanan Indonesia 15: 117-125. 